\title{
Das Haar in der Suppe
}

\section{Erhard Taverna}

Dr. med., Mitglied der Redaktion

Spielten Sie in der Jugend Indianerlis, sind Sie als Mann einmal auf einer Party als Frau aufgetreten oder umgekehrt als Frau, wie ein Mann, waren Sie an einem präpubertären Doktorspiel beteiligt? Es könnte nachträglich ihrer Karriereplanung schaden.

Als advocatus diaboli wird kirchenrechtlich ein Anwalt bezeichnet, der im Prozess der Heiligsprechung Belege und Argumente anfechtet, die eine Kanonisierung rechtfertigen. Ihm obliegt es, das berühmte Haar in der Suppe zu finden. Eine makellose Biografie scheint heute auch für Politiker unerlässlich. Wobei die Kriterien für ein Leben ohne Makel stets dem Urteil der Gegenwart unterliegen.

\section{Die Kriterien für ein Leben ohne Makel unter- liegen stets dem Urteil der Gegenwart.}

Helmut Schmidt, der deutsche Bundeskanzler, war die grosse Ausnahme, der ohne Ausflüchte zu seiner Nikotinsucht stand, wenn er bei jedem öffentlichen Auftritt seine Glimmstängel rauchte. Er überlebte seine Ärzte und besass genügend Autorität und Charisma, dass sich bei ihm Kritik verbat. Zwei Jahre vor seinem Tod bekannte sich der französische Präsident François Mitterand zu seiner unehelichen Tochter. Seinem Prestige hat es kaum geschadet, obwohl er seine aussereheliche Liebesbeziehung über viele Jahre verheimlichte. Quod licet Jovi non licet bovi, was Jupiter darf ist dem Ochsen nicht erlaubt. Was im alten Europa noch durchgehen mag, ist in den USA oder Kanada nicht denkbar. Das puritanische Erbe der Gründerväter scheint dort genetisch verankert.

Die berühmteste Drogenbeichte stammt vom ehemaligen US-Präsidenten Bill Clinton: Er habe Marihuana geraucht, aber nicht inhaliert. Also nur ein bisschen geschnuppert, keinesfalls mit Genuss konsumiert. Der bisher erfolgreiche Justin Trudeau kämpft um seine Wiederwahl zum kanadischen Premier, seit bekannt wurde, dass er 20 Jahre früher an einer Kostümparty mit dem Thema "Arabische Nächte» mit geschwärztem Gesicht als Aladin aus 1001 Nacht auftrat. Die Wunderlampe scheint er dringend zu brauchen, wenn er seine politischen Gegner ausmanövrieren will. Black Facing ist heute verpönt. Selbst Othello bleibt in seiner Rolle ungeschminkt, was kein Verlust ist. Empörte Aktivisten, die in den sozialen Medien unterwegs sind, lieben es, auch längst zurückliegende Verfehlungen $\mathrm{zu}$ skandalisieren. Peinlich wird es, wenn Angeschuldigte sich in den Staub werfen, auch für etwas, das nach vergangenen Massstäben unverfänglich war. Schmidt hatte da kein Problem. Es gibt noch mehr Beispiele, etwa wenn einer Popsängerin ihr schwarzes Schuhmodell vorgeworfen wird, weil es ein rassistisches Design aufweise. Was ist von Nike-Turnschuhen zu halten, die ein Logo tragen, das dem Namen Allahs in arabischen Schriftzeichen ähnlich sieht? H\&M musste Kindersocken aus gleichen Gründen aus dem Verkauf nehmen. Globale Unternehmen können keinen Shitstorm brauchen, right or wrong.

Ein falsches Schlachtfeld. Besser wäre es, ethnische oder religiöse Diskriminierung dort zu bekämpfen, wo sie traurige Realität ist, etwa beim Menschenhandel oder bei der Unterdrückung von Millionen Armeniern, Kurden, Berbern, Tibetern und Uiguren. Doch das schadet dem Geschäft. Die Rassismus-Obsession ist die Folge einer Identitätspolitik, die eine Person auf die sexuelle oder ethnische Identität festlegt. Wahre Diskriminierung erfolgt meist alltäglicher und subtiler. Der inflationäre Gebrauch des Rassismusvorwurfs trivialisiert den Begriff und spielt den echten Rassisten

\section{Der inflationäre Gebrauch des Rassismus- vorwurfs trivialisiert den Begriff und spielt den echten Rassisten in die Hände.}

in die Hände. Eine rigoros rückwärtsgewandte moralische Erwartung ist heuchlerisch, weil sie den Anschein gibt, mit kosmetischen Eingriffen tiefer liegende Probleme zu lösen. Der totale Anspruch auf eine makellose Lebensführung gehört zur Vita eines Heiligen. Ein Martyrium muss es dann schon sein oder ein klitzekleines Wunderchen. Das erwarten wir aber von keinem unserer Politiker. 